\section{DIGITAL COMMONS \\ @ UNIVERSITY OF SOUTH FLORIDA}

\section{Suburban Sustainability}

Volume 5 | Issue 1

Article 2

\title{
Towards Food Service Sustainability in Suburban Environments by Optimally Locating Shared Anaerobic Digester Units
}

\author{
Rebecca Loraamm \\ University of Oklahoma, rloraamm@ou.edu \\ Joni Downs \\ University of South Florida, downs@usf.edu \\ Robert Alonso Bair \\ University of South Florida, rbair@mail.usf.edu \\ Daniel Yeh \\ University of South Florida, dhyeh@usf.edu
}

Follow this and additional works at: https://digitalcommons.usf.edu/subsust

Part of the Environmental Education Commons, Geographic Information Sciences Commons, Spatial Science Commons, and the Transportation Engineering Commons

\section{Recommended Citation}

Loraamm, Rebecca; Downs, Joni; Bair, Robert Alonso; and Yeh, Daniel (2017) "Towards Food Service Sustainability in Suburban Environments by Optimally Locating Shared Anaerobic Digester Units," Suburban Sustainability. Vol. 5 : Iss. 1 , Article 2.

http://doi.org/10.5038/2164-0866.5.1.1031

Available at: https://digitalcommons.usf.edu/subsust/vol5/iss1/2

This Article is brought to you for free and open access by the Open Access Journals at Digital Commons @ University of South Florida. It has been accepted for inclusion in Suburban Sustainability by an authorized editor of Digital Commons @ University of South Florida. For more information, please contact digitalcommons@usf.edu. 
Towards food service sustainability in suburban environments by optimally locating shared anaerobic digester units 


\begin{abstract}
Anaerobic digestion is an effective method for reducing food waste at the consumer level. Drawbacks associated with this strategy include high construction costs for multiple digester units and limited public awareness of the method's commercial potential. Given the large scale problem of food waste, an approach establishing community partnerships between local businesses and primary schools is offered to combat the problem of food waste. Optimizing the placement of shared digester units enabling utilization by multiple stakeholders is the suggested mitigation method. This research explores application of the p-median problem to determine the set of optimal site(s) for shared anaerobic digester units among restaurants in a suburban setting, using schools as potential digester sites. The $p$-median problem was applied to determine optimal sites for locating these facilities in the study area. The p-median problem seeks to locate $p$ facilities at $i$ locations while minimizing the total transportation cost necessary to satisfy customer demand, where each customer is supplied from the closest facility. Five scenarios were evaluated, including runs with a $p$ equal to 1, 5, 10, 25 and 50 facilities respectively, using an estimated acceptable transportation distance of 250 meters between waste producers and digester facilities. Results were evaluated in terms of the number of producer locations serviced relative to the $p$ number of digester facilities desired. This application demonstrates how the $\mathrm{p}$ median problem can serve as a useful planning tool, providing options to planners interested in effective facilities placement for studies aimed at food waste reduction.
\end{abstract}

Keywords: location model, anaerobic digestion, food waste, optimization, community partnerships 


\section{Introduction}

The United States Environmental Protection Agency estimates that in 2012, 36 million tons of food waste were generated in the U.S. (US EPA, 2013). On the global scale, it is estimated that approximately one third of all food produced ends up being wasted rather than consumed (Gustavsson et. al., 2011). By weight, food waste constitutes the single largest category of material being sent to U.S. landfills and incinerators (USEPA 2013). Once in a landfill, this organic waste degrades and produces methane, which has over twenty times the global warming potential of carbon dioxide (IPCC 2006). With such large volumes of food being sent to landfills, it is understandable that food waste constitutes the third largest anthropogenic source of methane emissions in the U.S. (USEPA 2011). Aside from direct methane emissions, sequestered energy, labor and materials in wasted food must be considered in assessing the impact of landfilling food waste. Indeed, landfilling food waste means discarding the energy, water and nutrients required for the production, processing, storage, and transportation of the food that is wasted (Carucci, G. et. al. 2005). A conservative estimate by Cuellar and Webber (2010) states that approximately 2030 trillion BTU, or two percent of all energy used in the U.S., is energy used to generate food that is ultimately wasted. As the U.S. strives to reduce its greenhouse gas emissions and reduce its energy consumption, implementation of a policy focus on proper food waste management practice will be essential to achieving emission reduction goals.

While an overall reduction of food waste production is vital, some percentage of food will always be discarded (US EPA, 2013). This type of refuse can become less of an environmental problem if treated properly. For example, rather than send food waste to a landfill or incinerator, the waste can be composted or anaerobically digested (Carucci, G. et. al. 2005). Composting, which is the use of aerobic microbes to break apart the complex bonds in organic waste, is a reliable waste treatment technology that is often used to dispose of food waste in a municipal setting (Jara-Sameneigo et al., 2017). Additionally, composting is readily scalable and is commonly used at the household, neighborhood, and city-scale. Composting allows for the recycling of nutrients in food waste by converting the waste into a soil additive and fertilizer which can be used to grow new food or materials. Anaerobic digestion (AD), a process that uses anaerobic microbes to break down organic materials, allows for the recycling of nutrients while recapturing sequestered energy in the waste by producing biogas (Hartmann and Ahring, 2005). Biogas, which is primarily methane, can be used as a fuel source similar to natural gas or propane and can replace energy supplied by traditional fossil fuels. AD has been used throughout the world for the dual purposes of waste treatment and energy recovery (Agblevor et al., 2003, Karpiscak et al 1982). In some parts of the world this technology is very common. For example, in India and China over 34 million small-scale anaerobic digesters have been installed (Bruun et al. 2014). In the U.S., the technology is less commonly applied; however, when it is used it is almost exclusively realized as large digester systems which often service an entire agricultural facility (Bangalore et al., 2016).

While AD has some advantages to composting, it has greater maintenance and infrastructure requirements, as anaerobic digester systems often involve relatively complicated gas collection mechanisms and heaters for the active compost media. While several research efforts are underway aimed at designing effective low-cost AD systems, (Lansing et al., 2010, Marti-Herrero and Cipriano, 2012) AD usually necessitates a large 
digester, or gas-tight tank, to be constructed and may also require skilled personnel to maintain the digestion process (Maritza Macias-Corral et. al. 2008). These costs often determine the scale at which a digester can be economically viable. Due to high labor and material costs in the U.S., household or small scale digesters are generally cost prohibitive. However, neighborhood or community scale digesters, if properly placed, can benefit from reduced collection costs compared to city scale digesters. This is particularly true of areas with lower population densities (Comber et al., 2015). Collection costs can be further reduced if waste is only collected from large food waste generators such as restaurants, grocery stores, and other food stores. The byproducts of AD, including a fertilizer and soil additive, are particularly beneficial if they are produced close to areas which can use the byproducts, such as urban gardens or landscaping (Thompson, Wang and Li, 2013). Community scale digesters, which can be distributed throughout a city, can benefit from reduced distribution costs of their byproducts to potential users when compared to city scale digesters. Proper siting of an anaerobic digester can make the recovery of energy and nutrients from food waste an economically viable and sustainable food waste management strategy.

A pilot anaerobic digestion study is underway at Learning Gate (LG) Community School in Hillsborough County, Florida (https://www.learninggate.org/). LG is an environmentally-focused, LEED-platinum, charter school which has installed a fully operational AD unit onsite as part of a larger effort to design and implement a comprehensive food waste reduction program. Given this successful AD implementation and associated educational opportunities for students, LG provides the community at large with an example of the potential offered by AD for reducing food waste. Pursuant to duplicating this success, planning efforts should then aim to identify similar optimal, shared placement of anaerobic digester locations to attain maximum utility and community outreach, given limited funding to build the AD units. This can be a challenge in sprawl development areas such as Hillsborough County where great distances must be covered to operationalize a community-wide food waste reduction effort.

Sprawling land development is a common problem associated with siting facility locations. According to Burchell et al. (1998) sprawl is generally identified as a low-density, haphazard development pattern which extends outward from urban centers. Sprawling urban and suburban growth negatively impacts natural resources, increases infrastructure costs, and increases transportation time between locations (Ewing 1997; Squires 2002). These factors make it important to understand the causes and consequences associated with sprawl to mitigate its effects in a sustainable way. Location modelling can offer one approach for strategically siting shared anaerobic digesters amongst neighboring restaurants in an urban or suburban setting exhibiting this sprawl development pattern. Commonly used in operations research, facility location models strategically site infrastructure such as warehouses and major shipping locations. A great deal of variation in approach and implementation for these models exists (Revelle 2008 and Murray 2010); however, all respective model types share a common theme. Facility location models seek to assign the best locations available to new facilities given a set of candidate sites and known sources of demand. This is achieved by mathematically optimizing an objective function subject to a set of constraints, primarily distance (Church 2002). In the context of urban planning, facility location models can be used for siting shared AD units over large spatial scales. 
Locating shared anaerobic digester sites calls for an application of the p-median problem with the objective of locating candidate digester sites to serve existing restaurant locations, in consideration of known network-based distances between them. Following the logic employed during the pilot study at Learning Gate School, the p-median approach is demonstrated by locating shared anaerobic digester units for restaurants in Hillsborough County, Florida using local schools and universities as potential facility sites. The paper is organized as follows. Section 2 summarizes the p-median problem and demonstrates how it can be used to site anaerobic digester units using network distances. Section 3 applies the method to locate the units in Hillsborough County, Florida. Section 4 discusses the applicability of the model to other cities as well as the limitations associated with using this method.

\section{P-median approach for siting shared anaerobic digester units}

The p-median problem has been used to locate facilities in numerous urban planning scenarios including siting warehouses (Rosenwein 1994, Hansen and Jaumard 1997) and industrial facilities (Krarup and Pruzan 1983). In this study, the p-median problem was applied to determine optimal sites for locating shared anaerobic digester facilities in urban environments where sprawl is a common development issue. The objective would be to select digester locations that minimize the total transportation cost between food waste producers and shared digester sites. In practical terms, values for siting facilities are determined based on the proximity of the demand locations to candidate facilities. In this case, location selections are calculated on the basis of network distances between waste producers and candidate digester facility sites. Candidate locations for shared digester facilities are evaluated given a distance value for their effective range and the best set of proposed digester locations is returned.

The p-median problem selects locations for $p$ facilities along a network such that the total cost distance between the selected sites is minimized; it can be formulated as a linear integer programming problem as found in Daskin (1995) and Miller and Shaw (2001). The p-median formulation can also be found in Aremu, et al. (2012) where it was used to site municipal solid waste bins in a developing world urban neighborhood. In this study, the formulation was used to site shared anaerobic digester facilities in an urban environment. Here, minimization of total cost distance is synonymous with finding a configuration of digester locations enabling the maximum possible number of waste producers to effectively dispose of food waste. Digester locations are sited in consideration of their effective range, which is the maximum distance a food waste producer would be willing to travel for disposal purposes, a walking distance in this case (McCormack et al. 2010, Yang and Diez-Roux 2012). For a series of scenarios, $p$ digester facilities are located at a set of sites I minimizing the total transportation cost satisfying waste producers, with respect to the feasible distance producers are willing to travel to dispose of food waste.

\section{Locating shared anaerobic digester units in Hillsborough County, Florida}


The Florida development model is one of urban and suburban sprawl, that presents unique challenges for locating facilities over large areas. Hillsborough County in particular exhibits a textbook sprawl pattern as there are low density of residential housing developments rapidly expanding away from the urban center of Tampa. Tampa's central business district and surrounding areas have a high dependency on cars for transporting goods and services. A total of 388 restaurants (Infogroup Inc., 2012) and 489 schools (FGDL, 2012) exist within 1,266 square miles in Hillsborough County, all contributing wasted food with few sustainable options available for mitigating the food waste problem. These factors present a complex task of AD facility location; the mathematics associated with the pmedian approach would be difficult to implement without the assistance of computers. Using ArcGIS 10.3 and associated network-based optimization functionality, the p-median approach was effectively automated for this research. The objective of this research is to explore spatial strategies for locating shared anaerobic digester units in Hillsborough County, Florida. The p-median problem was applied to determine the optimal set of potential facility sites, maximizing covered demand based on surrounding restaurants which generate significant amounts of food waste.

\subsection{Study Area \& Data}

First, potential food waste generators in Hillsborough County Florida were inventoried; this included restaurants, as these business types are understood to be the largest commercial contributors to food waste. Next, potential anaerobic digester locations were inventoried, this included candidacy for both public and private primary schools and universities. Since the Learning Gate School operates as a successful example partnership between schools and the surrounding community, other local schools should be explored as candidates providing similar partnership to other parts of Hillsborough County and surrounding communities. For this reason, school locations were used as potential facility sites, illustrating the concept of a community partnership towards sustainable food waste outcomes. Future studies may wish to use other potential facility criteria, however in this case, schools are relatively evenly distributed throughout Hillsborough County and are more likely to provide the technical resources and educational emphasis necessary to support shared $\mathrm{AD}$ units onsite. The spatial locations of these demand and potential facility nodes were mapped using ArcGIS 10.3.

\subsection{P-median Application}

Using the network analyst extension for ArcGIS, the p-median problem was applied to determine optimal sites for locating AD facilities in Hillsborough County at varying amounts of $p$ sites to locate. The model was run for five scenarios, where $p$ was equal to 1 , $5,10,25$ and 50 facilities located, each with an estimated facility effective range of 250 meters, respectively. While the chosen facility effective range may vary depending on situational and location requirements, 250 meters was chosen because it represents an average walking distance between waste generation points and candidate facility locations. For each scenario, the model was solved returning the set of $p$ optimal placements for facilities, these configurations maximize the number of restaurant locations serviced, given 
the effective range of AD units. Initial preprocessing for this analysis involved identification of candidate sites and demand locations along the major roads in Hillsborough County. This was accomplished by snapping school locations to the road network providing for the set of candidate locations. Similarly, demand locations (restaurants), were snapped to the road network as well. Coincidence of site and candidate facility point locations to the roadway network provided network based distances as required by the formulation. A minimize impedance tool provided as part of Network Analyst was used to locate $p$ facilities at candidate locations resulting in five distinct scenarios minimizing transportation cost between demand locations and selected candidate facilities. The model results were evaluated in terms of the number of demand locations serviced versus $p$ number of AD facilities provided. Results were mapped in GIS for visualization and discussion.

\section{Results}

The model results were evaluated in terms of the number of demand locations serviced versus $p$ number of facilities provided, with respective configurations of $p$ facilities representing the maximum $\mathrm{AD}$ location access to restaurants possible given the applicable walking distance along the network. The resulting objective values for each p-median scenario for siting shared AD units are summarized in Table 1. The value of $p$ indicates the number of proposed new shared AD units to be sited while the value of $i$ indicates the number of restaurants serviced by these facilities in each scenario at an effective range (walking distance) of 250 meters. For example, for $p=5$ facilities, the approach yielded a configuration for digesters serving a total of 78 restaurants within a 250 -meter network distance. When the $p$ value is increased to 10 , the number of restaurants serviced increased to 128 .

Table 1. Number of restaurants served by $p$ number of facilities.

\begin{tabular}{cc}
\hline Number AD facilities built $(p)$ & Number of restaurants covered $(i)$ \\
\hline 1 & 19 \\
5 & 78 \\
10 & 128 \\
25 & 230 \\
50 & 335 \\
\hline
\end{tabular}

The increase in number of restaurants serviced by each additional $p$ facility site is reduced with increasing the number of shared AD sites ( $p$ facilities) to be located. This is because as the number of restaurants serviced increases, the proposed AD sites become more spatially spread out. For example, when only one shared AD is sited, 19 restaurants are serviced; however, when five shared AD's are sited, only 15.6 restaurants are serviced on average per site; with $10 \mathrm{AD}$ facilities an average of 12.8 per site are serviced and with 25 facilities only an average of 9.2 are serviced with each new AD unit. This pattern was observed at each scenario, more AD sites implemented meant fewer food waste producers serviced per unit over larger spatial distances. Illustrating this relationship, Table $1 \mathrm{can}$ 
serve as a reference guide to sustainability planners deciding on the number of shared units required to optimally service surrounding restaurants given limited funding availability and the needs of community stakeholders. For example, if the number of AD units implemented must be able to service a minimum of 15 restaurants on average per unit within the defined network service distance, siting any more than 5 units would not be considered economically practical. Spatial locations and distributions of these sites are illustrated in Figure 1 (Appendix). In this scenario, new structures are primarily sited along road networks in the north central and western part of Hillsborough County. Figures 2-5 (Appendix) show the spatial locations and distributions of the sites in the remaining scenarios.

\section{Discussion and Conclusions}

The results of this research illustrate how the p-median approach can be used to strategically site shared anaerobic digester units based on spatial patterns of restaurant demand for servicing of food waste. This application demonstrates how the p-median problem can serve as a useful design and planning tool when limited funding is available. This approach represents an inexpensive approach providing a range of options to planners looking to effectively reduce food waste towards meeting shared sustainability goals at the community level. An advantage to using the p-median technique is that the results explicitly identify the optimal locations for AD facilities, based on number of feasible facilities, as well as directly quantify the number of restaurant sites that can be serviced by each additional AD facility constructed. The output also reveals which new facilities, and how many of them, would be needed to service all restaurants. In this study, a large proportion could be covered with only a limited number of new AD facilities. While it is unclear whether funds for building new $\mathrm{AD}$ facilities alleviating food waste will be available in the near future, this research can help planners in determining priority locations for future development in Hillsborough County. Further, optimal site suggestions provided by this approach could be used to support justification for future funding.

The p-median application utilizes network distances, capturing the actual cost of servicing food waste demand more realistically than Euclidean or straight-line distance optimization approaches. While the transportation distance of 250 meters can be used as a reference, the actual distance may vary depending on the given study area or analysis parameters. This should be considered in future studies seeking to utilize this approach. Additionally, an optimal solution for Hillsborough County does not necessarily reflect an optimal solution for all situations. Planners employing the p-median approach should consider mitigation goals and set thresholds to minimize costs in a way that suits the needs of their study area, based on their own assessment of existing conditions in conjunction with the amount of funds available.

Schools were used as potential facility sites in this case based on the successful implementation of an AD unit at Learning Gate, as well as the prospective educational initiatives associated with informing the community at-large about an alternative for combating food waste. However, these partnerships at future sites may take several forms. One direct use is that schools could serve as a waste processing site for local restaurants that may not find it feasible or are hesitant to build an AD unit onsite. While certain safety concerns must be addressed before pursuing this option, such as the transport of waste or 
other health and legal concerns, this provides a direct means of disposing of waste at the consumer level and reducing the amount of food that is sent to the local landfill. Location modelling provides a means for effectively covering demand based on the strongest areas of food waste production. Another, less direct use is that schools can serve as a center for community outreach. Schools can provide a learning opportunity to encourage food waste reduction in surrounding restaurants by providing information about $A D$, and by offering a unit as a functional demonstration of food waste processing. This may provide an incentive for restaurants to potentially implement similar smaller units of their own onsite. While the units themselves in this case are not necessarily shared, the concept and ideas behind $\mathrm{AD}$ can have a cascading effect into community-level food waste reduction; location modelling provides an effective strategy on how to disperse this information.

To conclude, the p-median approach presented in this research provides a convenient and easy to use tool for strategically locating shared AD structures in settings where urban sprawl has increased transportation time and associated economic and environmental costs. Anaerobic digesters reduce the total amount of food waste in an urban area by reducing the amount of food sent to landfills. Given the limited availability of funding for these projects, planners can utilize the p-median problem to objectively select the best sites for shared $\mathrm{AD}$ units such that the cost of serving surrounding restaurants is minimized while simultaneously assessing the advantages and disadvantages to building new units.

\section{References}

American Society of Civil Engineers, 2013 Report Card for American Infrastructure. 2013, ASCE: http://www.infrastructurereportcard.org/wpcontent/uploads/2013ReportCardforAmericasInfrastructure.pdf

Aremu, A.S., Sule, B.F., Downs, J., \& Mihelcic, J.R. (2012). Framework to determine the optimal number and spatial location of municipal solid waste bins in a developing world urban neighborhood. Journal of Environmental Engineering, ASCE, 138(6), 645-653.

Bangalore, M., Hochman, G. \& Zilberman, D. (2016). Policy incentives and adoption of agricultural anaerobic digestion: A survey of Europe and the United States. Renewable Energy, 97, 559-571.

Bruun, S., Lars Stoumann, J., \& Sommer, S. (2014). Small-scale household biogas digesters: An option for global warming mitigation or a potential climate bomb?. Renewable and Sustainable Energy Reviews 33, 736-741.

Carucci, G., Carrasco, F., Trifoni, K., Majone, M., \& Beccari, M., (2005). Anaerobic digestion of food industry wastes: effect of co-digestion on methane yield. Journal of Environmental Engineering 131 (7), 1037-1045.

Church, R. L. (2002).Geographical information systems and location science. Computers Operations Research, 29(6), 541-562.

Cuellar, A.D. \& Webber, M.E. (2010). Wasted food, wasted energy: the embedded energy in food waste in the United States. Environmental Science and Technology, 44(16), 6464-6469.

Daskin, M. S. (1995). Network and Discrete Location: Models, Algorithms and 
Applications. New York, John Wiley and Sons.

Florida Geographic Data Library. Florida Public and Private Schools 2012. Retrieved October 30, 2012, from fgdl.org

Gustavsson, J., Cederberg, C., Sonesson, U., van Otterdijk, R., \& Meybeck, A. (2011). Global Food Losses and Food Waste: Extent, causes and Prevention. Food and Agriculture Organization of the United Nations: Rome.

Hansen, P. \& Jaumard, B. (1997). Cluster Analysis and Mathematical Programming. Mathematical Programming 79, 191-215.

Hartmann, H. \& Ahring, B.K. (2005). Anaerobic digestion of the organic fraction of municipal solid waste: influence of co-digestion with manure. Water Resources, 3 , 1543-1552.

Infogroup, Inc. US Businesses. Retrieved October 1, 2012, from Reference USA database. IPCC, (2006). 2006 IPCC Guidelines for National Greenhouse Gas Inventories. The National Greenhouse Gas Inventories Programme, The Intergovernmental Panel on Climate Change, H.S. Eggleston, L. Buendia, K. Miwa, T Ngara, and K. Tanabe (eds.). Hayama, Kanagawa, Japan. $9^{\text {th }}$ Corrigenda (2015).

Jara-Samaniego, J., Perez-Murcia, M.D., Bustamante, M.A., Perez-Espinosa, A., Paredes, C., Lopez, M., Lopez-Lluch, D.B., Gavilanes-Teran, I., \& Moral R. (2017). Composting as sustainable strategy for municipal solid waste management in the Chimborazo Region, Ecuador: Suitability of the obtained composts for seedling production. Journal of Cleaner Production, 141, 1349-1358.

Krarup, J. \& Pruzan, P. (1983). The simple plant location problem: survey and synthesis. European Journal of Operations Research 12, N1, 36-81.

Lansing, S., Martin, J.F., Botero, R.B., Nogueira da Silva, T., \& Dias da Silva, E. (2010). Methane production in low-cost, unheated, plug-flow digesters treating swine manure and used cooking grease. Bioresource Technology, 101, 4362-4370.

Marti-Herrero, J., \& Cipriano, J. (2012). Design methodology for low cost tubular digesters. Bioresource Technology, 108, 21-27.

Macias-Corral, M., Samani, Z., Hanson, A., Smith, G., Funk, P., Yu, H., \& Longworth, J. (2008). Anaerobic digestion of municipal solid waste and agricultural waste and the effect of co-digestion with dairy cow manure. Bioresource Technology, 99, 8288-8293.

Miller, H. J., \& Shaw, S. L. (2001). Geographic information systems for transportation: principles and applications, Oxford Univ. Press, NY.

Rosenwein, M.B. (1994). An application to of cluster analysis to the problem of locating items within a warehouse. Institute of Industrial Engineers Transactions. 26(1), 101103.

U. S. Environmental Protection Agency. Municipal Solid Waste in the United States: 2012 Facts and Figures. 2013. http://www.epa.gov/osw/nonhaz/municipal/pubs/2012 msw fs.pdf

United States Environmental Protection Agency. Office of Atmospheric Programs., Inventory of U.S. greenhouse gas emissions and sinks: 1990-2009. 2011, Washington, D.C.

Yang, Y. \& Diez-Roux, A. V. (2012). Walking Distance by Trip Purpose and Population Subgroups. American Journal of Preventive Medicine. 43(1)11-19. 


\section{Appendix:}

Figure 1. Spatial locations and distributions of potential AD sites for the one facility site scenario

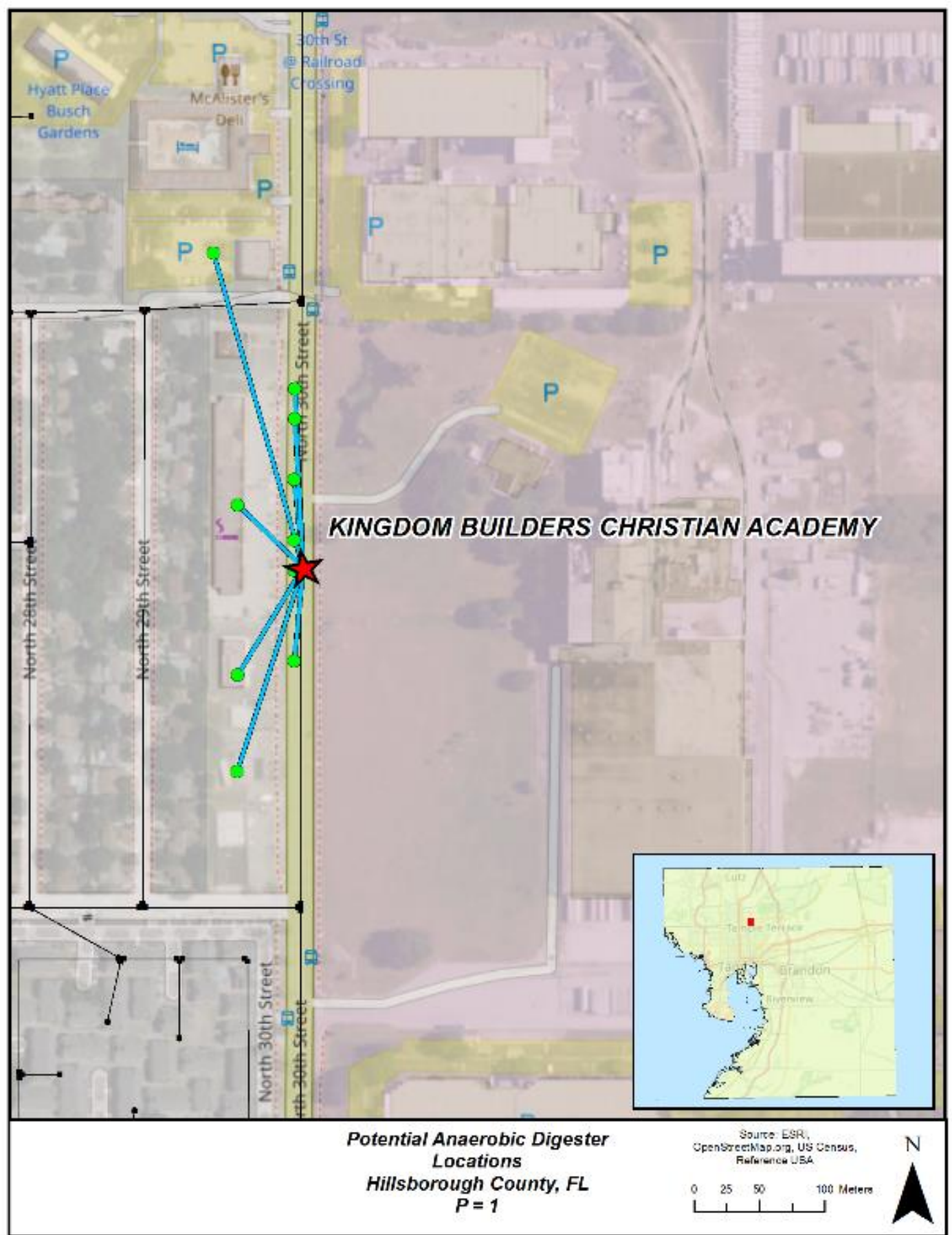


Figure 2. Spatial locations and distributions of potential AD sites for the five facility site scenario

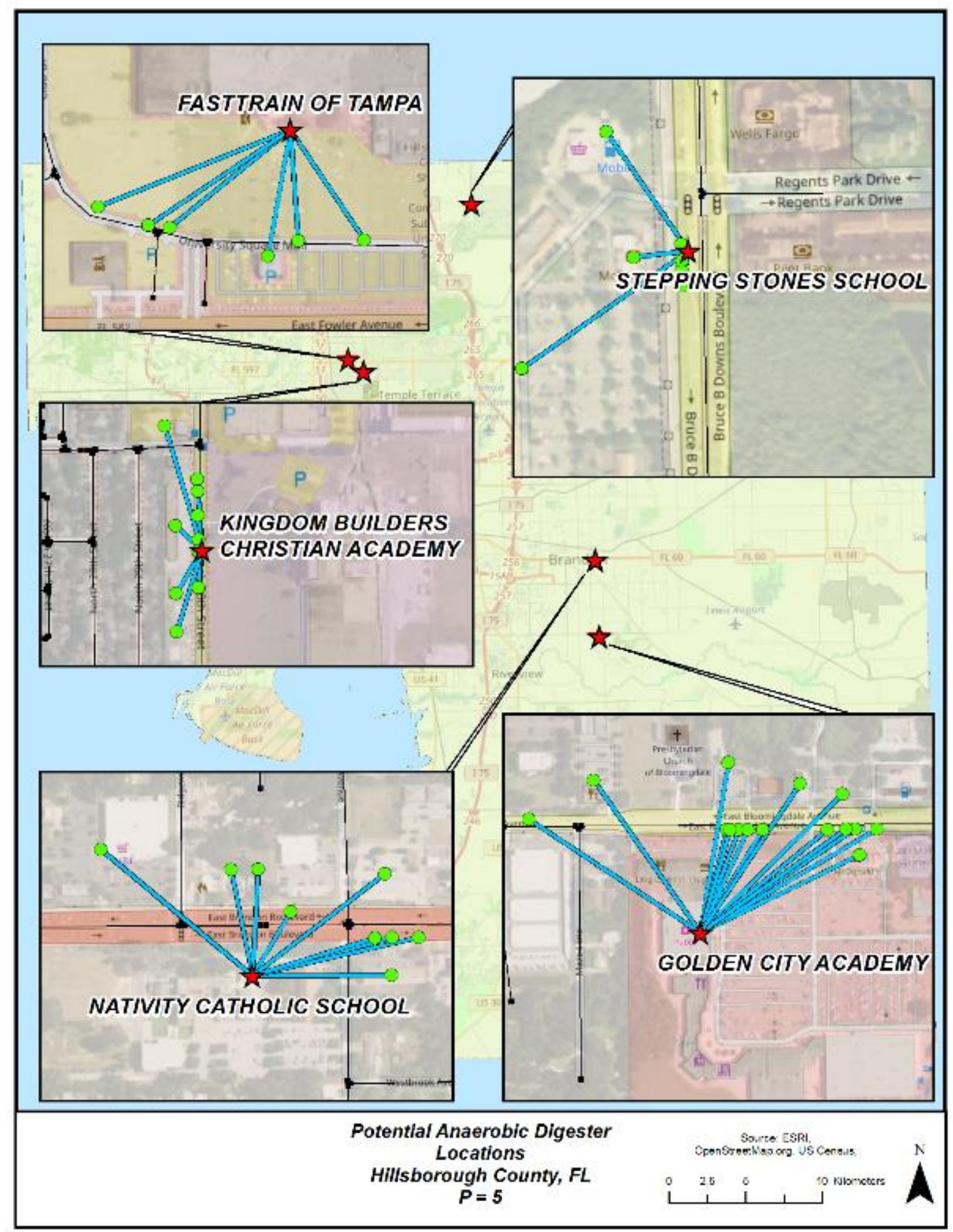


Figure 3. Spatial locations and distributions of potential AD sites for the ten facility site scenario

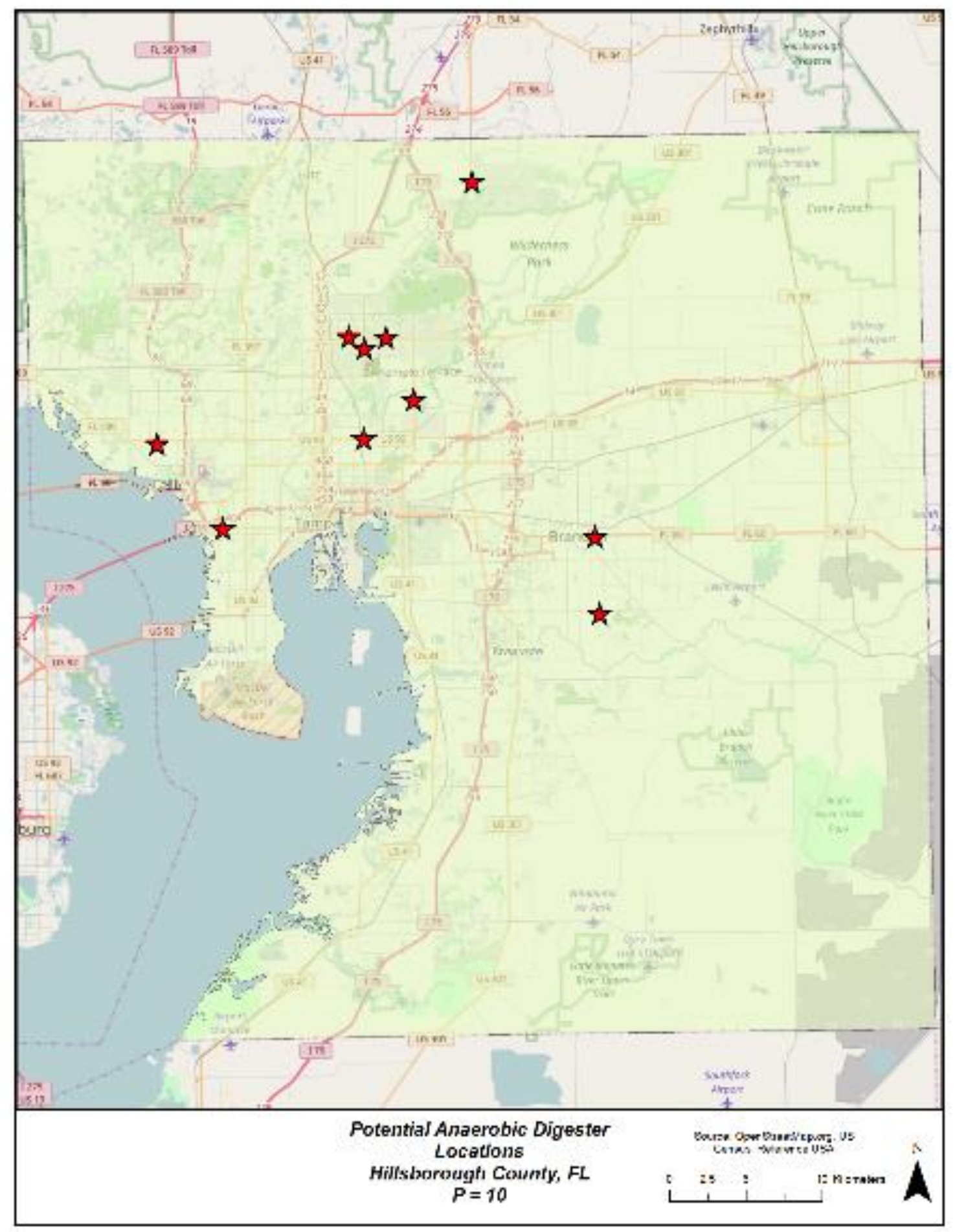


Figure 4. Spatial locations and distributions of potential AD sites for the 25 facility site scenario

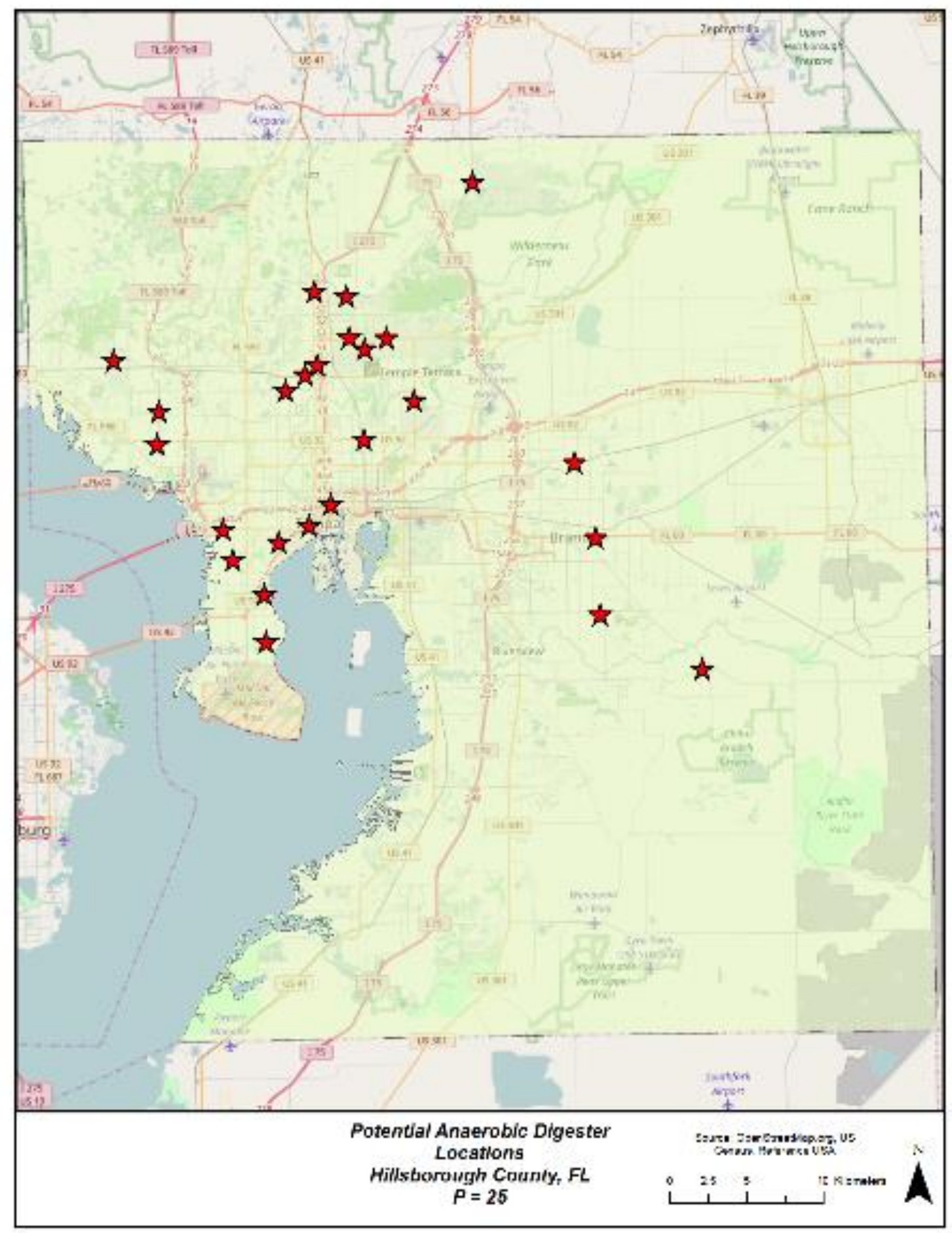


Figure 5. Spatial locations and distributions of potential AD sites for the 50 facility site scenario

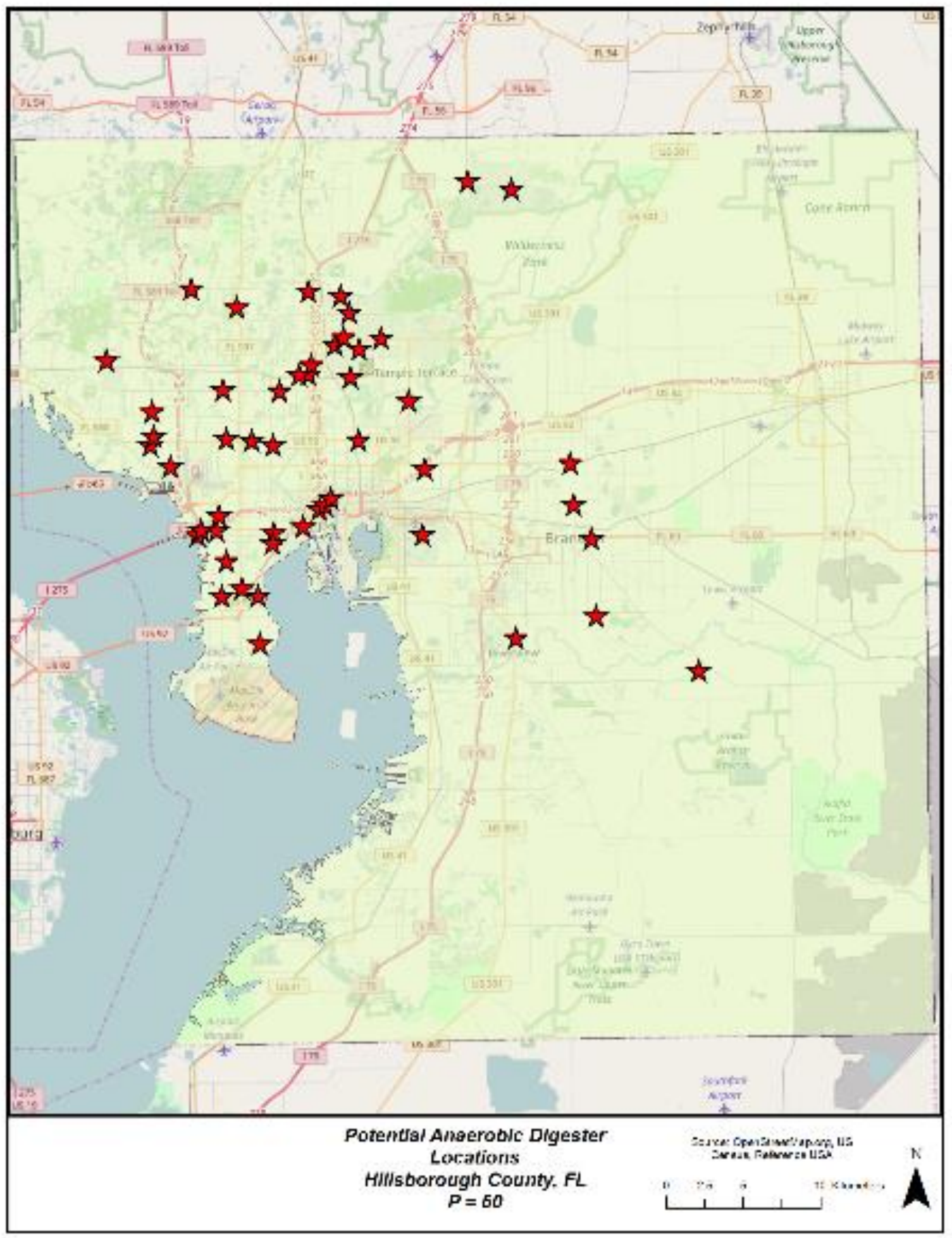

